\title{
Innovative Energy Clusters' Infrastructure
}

\author{
Submitted $25 / 03 / 20,1^{\text {st }}$ revision $18 / 04 / 20,2^{\text {nd }}$ revision $28 / 05 / 20$, accepted $30 / 07 / 20$
}

\section{Abstarct:}

\section{Olga Bergal ${ }^{1}$}

Purpose: The purpose of the study is to develop recommendations for the creation of systemic, open, interactive data on innovative energy clusters, allowing cluster managers to build inter-cluster relationships, to assess the impact of clusters on economic development. Design/Methodology/Approach: The methodology is based on the conceptual provisions of the works of foreign and Russian scientists on the research topic. Using the methods of grouping and comparative analysis of statistical data, we analyzed the volume of electricity production and production of alternative energy in calculation on one inhabitant of the leading energy powers in the world. We also conducted a comparative analysis of databases Clustered Russia map, Cluster map of the US and European cluster maps, were studied the dynamics of the development of innovative energy clusters. Data are from the Global Energy Statistical Yearbook, government statistics, data of the Russian Cluster Observatory, the US Cluster Mapping and the European Cluster Observatory.

Findings: Innovative energy clusters are mainly created on the basis of large generating and transmission energy companies. These clusters specialize in the production of bioenergy, introduce energy-saving technologies, increase energy efficiency, diversify the national energy system, and ensure the economic growth of the territories. The development of innovative energy clusters depends on the solution of a number of problems. In the study it has formulated the following ways of solving problems. Creation of an interactive cluster map that accumulates a complete database of cluster entities. Clarification of specialization groups of Russian clusters used in the course of cluster mapping, taking into account comparable groups of specializations of American and European clusters. Development of recommendations for the creation of an interactive resource of systemic, open, data on cluster formations.

Practical Implications: The results and recommendations are addressed to developers of regional cluster policy, strategic planning documents, and cluster managers, and can also be used in the process of creating an interactive cluster map of Russia.

Originality/Value: Recommendations were developed for the development of innovative energy clusters that ensure an increase in bioenergy production and economic growth.

Keywords: Innovative energy clusters, clusters of related industries, cluster's specialization, bioenergy, renewable energy sources, cluster mapping.

JEL: O38, Q420, R58, D25.

Paper Type: Research article.

\footnotetext{
${ }^{1}$ School of Public Administration, NRU "Higher School of Economics”, Moscow, Russia, e-mail: olyabergal@gmail.com
} 


\section{Introduction}

The global processes of regions' modern economic and social development are associated with energy resources. Energy increasingly dominates all aspects of human life and becomes the main capital for the state development and modernization (Demirbas, 2016). In modern conditions, the economy growth and industries' competitiveness are carried out through innovation. Innovations are created and implemented mainly in clusters, in the process of well-coordinated interaction of science, business, government, during the process of developments' approbation and implementation. The creation and development of innovative energy clusters is a "natural" process. An innovative energy cluster is understood as a set of organizations from related industries, including a large energy company, a research center that receives financial support from the government, a branch of an infrastructure company in the energy industry, a cluster organization, and other participants.

The research topic relevance is determined by the importance of introducing innovations in the energy sector, developing bioenergy, ensuring the diversification of the energy system through renewable energy sources, developing innovative energy clusters, improving cluster mapping and cluster specializations.

Despite numerous publications on the theoretical and methodological foundations of economic clustering and empirical research on the energy industry development, the issues of assessing the impact of innovative energy clusters on economic growth have not been fully studied. To achieve the goal is importance to solve the following tasks: to develop recommendations for creating systematic, open, interactive data on innovative energy clusters, allowing to build inter-cluster relationships and assess their impact on the development of the economy; to study the prospects for the innovative energy cluster development on the basis of generation and network utilities; to clarify the mechanism of formation of information about the energy cluster on the cluster map of Russia; to study the possibility of drawing up uniform groups of specialties of the Russian clusters used in the process of mapping; to compose the network of a chain of innovative energy clusters of related industries; to outline the ways of innovative energy clusters development.

\section{Development of Energy Clusters: Literature Review}

A growing body of empirical literature has shown a positive impact of clusters on regional and industry indicators of new jobs, innovations and new business creation (Delgado et al., 2014). Questions about the place and role of the government in the process of cluster development, cluster policy, cluster management tools are actively discussed by specialists and have an interdisciplinary nature (Glăvan, 2008; Tsathlanova et al., 2015; Larionova et al., 2018; Konstantynova, 2019). The study of clusters and their impact on economic development is carried out using cluster mapping and statistical models. Porter in 2000 developed a model that can 
statistically define and describe clusters in the economy. Subsequently, the groupings of traded (interregional) and local clusters were described. Based on this model, a statistical correspondence table was developed that allows the use of American cluster specialization codes for European data (Delgado et al., 2014). The first mapping in Europe was carried out for Sweden in 2003 (Sölvell et al., 2009).

Cluster specialization codes are currently used by the American and European Cluster Observatories. The scientific work of Delgado et al. (2014) substantiated that the industries participating in a strong cluster show higher growth in employment, wages, the creation of new organizations and patents. It is also proven that new industries emerge where there is a strong cluster environment. In scientific works (Koytsoumpa et al., 2016; Kalmykova et al., 2016), positive trends in the development of clusters in the energy industry are noted; modernization and growth of innovations, reducing the use of traditional energy resources in Europe. The most competitive energy clusters are located in Finland and Germany, countries with minimal economic risks and relatively low bureaucratic barriers (Kousoulidou et al., 2016; Schanes et al., 2019; Mikova et al., 2019).

Among Russian scientists, works are devoted to the theoretical and methodological foundations of clustering economics (Glazyev, 2011; Gokhberg, 2016; Golovanova and Avdasheva, 2010; Kutsenko, 2015; Markov, 2006; Melnik, 2013; 2019; Sheresheva, 2008; Tretyak, 2006; Tsikhan, 2003). Melnik (2019) believes that the effectiveness of the creation and functioning of clusters is largely determined by the stability of the national political system and the comfortable conditions for doing business in the country. Kleiner (2018) examines the development of industrial ecosystems that combine the features of clusters, holdings, financial and industrial groups, technology parks and business incubators. Kapitonov et al. (2017) consider the benefits of integrating small and medium-sized enterprises into energy clusters versus integrating into large energy corporations. In the first scenario, there is cooperation between small and medium-sized enterprises and big business, as well as the contribution of small and medium-sized businesses to the creation of innovations, the restoration and growth of the Russian energy sector. In the second case, small and medium-sized businesses are absorbed by large energy companies (Kapitonov et al., 2017).

It has been proven that startups provide the largest growth in innovation in the energy sector (Iazzolino, 2019). The development of energy clusters is carried out within the framework of the implementation of state and interstate energy strategies. At present, during the discussion of the draft energy strategy of the Russian Federation until 2035, experts note some shortcomings. The main ones are: orientation towards an export-oriented model of energy development; increased production of carbon resources and insufficient attention to the growing role of renewable energy sources (Alekseev et al., 2019). In continuation of this topic Tyaglov et al. (2019) consider the development of alternative energy as one of the strategic priorities of state policy. The authors believe that the creation of clusters of 
renewable energy sources will reduce the burden on the environment, help optimize the structure of the country's energy balance, and ensure the innovative development of the energy industry for the long term. Fakhrutdinova et al. (2016), based on the results of a regression-correlation analysis of the impact of the activities of the main energy clusters in Russia on the socio-economic indicators of the regions, revealed the dependence of the growth of the gross regional product on the rate of cluster development. Based on the results of this research, it was concluded that energy clusters contribute to the development of interregional relations, doing possible to maneuver the produced resources in time and space in the conditions of a large length of the country and the mismatch of peak loads in certain parts of the energy systems.

\section{Methodology}

The methodological basis of the study is based on the conceptual provisions presented in the works of Russian and foreign scientists on the study of development and impact of energy clusters on regional economy. The paper reviews scientific publications on the research topic, containing recommendations that can be used in the development and updating policy documents for the support and development of energy clusters in Russia. General scientific, theoretical and empirical research methods were used to solve the set tasks as analysis and synthesis, observation and modeling, factor analysis. The materials and information base of the study were financial reports of generating and transmitting energy companies in Russia, data from the Cluster Observatory of Russia ${ }^{2}$, US Cluster Observatory $^{3}$, European Cluster Observatory ${ }^{4}$, government statistics data for 2010$1018^{5}$, Technological platform in the areas of scientific and technological development, energy, nuclear and radiation technologies ${ }^{6}$, Ministry of Energy of the Russian Federation ${ }^{7}$, official websites of Russian clusters, as well as reports of a number of cluster development centers.

\section{Results}

Industrial production consumes about $90-93 \%$ of world's energy. The level and quality of energy supply determines the conditions for production activities and ensure the livelihoods of the population, which determines the importance of the development of the industry for the economy. Russia is the fourth energy market in the world in terms of electricity production and consumption after China, the USA

\footnotetext{
${ }^{2}$ Russian Cluster Observatory. https://cluster.hse.ru/.

${ }^{3}$ US Cluster Mapping. https://clustermapping.us.

${ }^{4}$ European Cluster Collaboration Platform. https://www.clustercollaboration.eu/.

${ }^{5}$ Federal State Statistics Service (Rosstat). Statistical publications. https://www.gks.ru/folder/210.

${ }^{6}$ Web-portal Innovation in Russia. Technological platforms. http://www.innovation.gov.ru/taxonomy/term/546.

${ }^{7}$ Web-portal of the Ministry of Energy of the Russian Federation. https://minenergo.gov.ru/.
} 
and India (Figure 1).

Figure 1. Electricity production by country in 2016, bln $\mathrm{kWh}$.

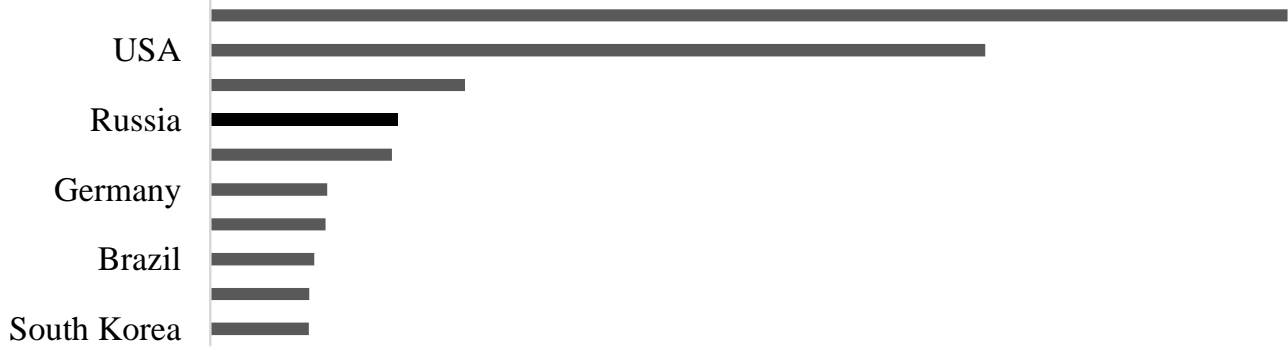

Source: Based on the Global Energy Statistical Yearbook 2017.

The electric power industry is one of the basic sectors of the Russian economy and is one of the ten industries with the largest contribution to GDP. In 2016, 1,049 bln $\mathrm{kWh}$ were generated and the growth rates increased in subsequent years. Data about dynamics of electricity production by interconnected energy systems and energy zones in 2017-2019 in Russia allow to talk about significant differences in the volumes of electricity generation in the regions of Russia (Table 1).

Table 1. Electricity production by interconnected energy systems and Energy zones in Russia

\begin{tabular}{|l|l|l|l|}
\hline Indicators & $\begin{array}{l}\mathbf{2 0 1 7}, \\
\text { bln } \mathbf{k W h}\end{array}$ & $\begin{array}{l}\mathbf{2 0 1 8 ,} \\
\text { bln } \mathbf{k W h}\end{array}$ & $\begin{array}{l}\mathbf{2 0 1 9 ,} \\
\mathbf{b l n} \mathbf{k W h}\end{array}$ \\
\hline European part and the Urals' Energy zone & 814,4 & 828,0 & 828,0 \\
\hline Siberia's Energy zone & 202,7 & 205,3 & 208,7 \\
\hline East's Energy zone & 36,8 & 37,6 & 43,8 \\
\hline Russia, total & $\mathbf{1 0 5 3 , 9}$ & $\mathbf{1 0 7 0 , 9}$ & $\mathbf{1 0 8 0 , 6}$ \\
\hline
\end{tabular}

Source: Compiled according to the data of the Ministry of Energy of the Russian Federation, 2017-2019 ${ }^{8}$

In 2019, 76.6 percent of the total electricity volume was generated in the European part of Russia and the Urals, in Siberia 19.3 percent, in the East 4.1 percent. The same significant differences are in production volumes depending on the types of electricity production. In the era of global environmental problems, the types of electricity produced are an important indicator for any state. The aggravation of the problems caused by climate change has drew criticism of traditional energy sources as they damage the Earth's ecosystem. That is why the transition to alternative

\footnotetext{
${ }^{8}$ Web-portal of the Ministry of Energy of the Russian Federation. Main characteristics of the Russian power industry. https://minenergo.gov.ru/node/532.
} 
energy is the best option for the development of events, both for humans and for nature. Alternative sources of electricity generation are wind power, the energy of the ebb and flow, energy of sunlight, geothermal energy, and bioenergy. In terms of electricity production per capita in 2016, Russia was in the second place after the United States. China $(\mathrm{CN})$ ranked fourth after the United States (US), Russia (RU) and the United Kingdom (UK) (Figure 2).

Figure 2. The volume of production of alternative electricity per capita in 2016, million $\mathrm{kW}$.

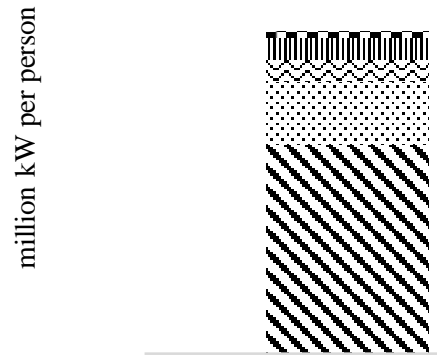

US

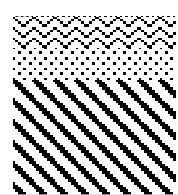

$\mathrm{RU}$

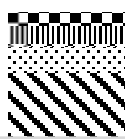

UK

Electricitv from biofuels and recreation

Source: Based on Rosstat Data ${ }^{9}$

Electricity generation from renewable sources excepting hydroelectricity was not practically produced in Russia. The main reasons are high production costs and the lack of necessary innovative developments. The Russian business community and the state realizing the importance of solving environmental problems are implementing strategic projects for the development of bioenergy. At the end of 2019 , we can note a positive trend in electricity generation from renewable sources (Table 2).

Table 2. Electricity balance in Russia

\begin{tabular}{|l|l|l|l|}
\hline Indicators & $\begin{array}{l}\mathbf{2 0 1 8}, \\
\text { bln } \mathbf{k W h}\end{array}$ & $\begin{array}{l}\mathbf{2 0 1 9}, \\
\text { bln } \mathbf{k W h}\end{array}$ & $\begin{array}{l}\mathbf{2 0 1 9} / \mathbf{2 0 1 8}, \\
\text { \% }\end{array}$ \\
\hline Electricity generation, total & $\mathbf{1 0 7 0 , 9}$ & $\mathbf{1 0 8 0 , 6}$ & $\mathbf{0 , 9}$ \\
\hline $\begin{array}{l}\text { including: Thermoelectric power } \\
\text { stations }\end{array}$ & 681,8 & 679,9 & $-0,3$ \\
\hline Water-power plants & 183,8 & 190,3 & 3,6 \\
\hline Nuclear power plants & 204,4 & 208,8 & 2,2 \\
\hline Wind power plants & 0,22 & 0,32 & 47,3 \\
\hline Solar power plants & 0,8 & 1,3 & 69,4 \\
\hline
\end{tabular}

\footnotetext{
${ }^{9}$ Federal State Statistics Service (Rosstat) (2018). Statistical collection "Russia and the countries of the world". https://www.gks.ru/free_doc/doc_2018/world18.pdf.
} 


\begin{tabular}{|l|l|l|l|}
\hline Electricity consumption & $\mathbf{1 0 5 5 , 6}$ & $\mathbf{1 0 5 9 , 4}$ & $\mathbf{0 , 4}$ \\
\hline $\begin{array}{l}\text { The balance of electricity flows "+" - } \\
\text { reception, } \\
\text { "-" - delivery }\end{array}$ & $-15,4$ & $-21,2$ & 37,9 \\
\hline
\end{tabular}

Source: Compiled according to the Ministry of Energy of the Russian Federation ${ }^{10}$

In 2019, compared to 2018 in Russia, electricity generation as a whole increased by 0.9 percentage points and amounted to $1080.5 \mathrm{bln} \mathrm{kWh}$. At the same time, the growth of energy generated by solar power plants amounted to 162.5 percent, wind power plants 145.5 percent.

The generating energy companies of Russia take part in the development of cluster formations to one degree or another. For example, Rosenergoatom Concern JSC, the Russian Federal Nuclear Center, and the Development Center Autonomous NonProfit Organization are members of the Sarov Innovation Cluster of the Sarov Innovation Cluster of the Nizhny Novgorod Region. The development strategy of RusHydro Group provides for interaction with the Innovation-Territorial Cluster "Cluster of Nuclear Physics and Nanotechnologies in Dubna" and the cluster of energy efficient technologies of the Skolkovo Foundation. OOO Gazprom Energoholding plans to assist in the establishment and development of the Digital Energy cluster in the Novosibirsk Region. Russian grid companies also have great potential for participation in cluster education. The rational behavior of economic agents objectively leads to the concentration of economic resources precisely in the industries of specialization, at the same time using the opportunities provided by the demand for the specialized core for the products and services of the auxiliary socioeconomic regional complex (Minakir, 2019).

The introduction of innovations in domestic generating and transmission energy companies is the most important condition for their technological development and ensuring competitiveness. The high capital intensity of innovative processes in the electric power industry, combined with the significant investment potential of energy companies, makes it possible to consider the industry as one of the largest customers for the creation of innovative technologies necessary to create industries that ensure the generation of electricity from renewable sources (Melnik, 2019). Generating and grid energy companies of Russia, along with other investors, may be the customers of such technologies.

On the one hand, cluster mechanisms contribute to the development of competition between its individual participants, stimulating their innovative activity. On the other hand, they allow to consolidate the common efforts of cluster members to confront the challenges of the external environment, creating the necessary prerequisites for the development of foreign sales markets.

\footnotetext{
${ }^{10}$ Web-portal of the Ministry of Energy of the Russian Federation. Main characteristics of the Russian power industry. https://minenergo.gov.ru/node/532.
} 
Each cluster is a complex economic structure, the development of which should be based on a strategic approach. In turn, the development of a strategy and program for the development of a cluster is a necessary condition for its state support. It is in the process of developing strategic documents that the interests of enterprises are coordinated, the key directions for the development of the cluster and strategies for the participation of enterprises in cluster ties are selected (Kostenko, 2016; Kapoguzov et al., 2019). Cluster management is also based on a process approach, which allows you to concentrate resources and use them effectively in the implementation of key business processes that ensure the achievement of planned results (Bulyarsky et al., 2012). The existing or created clusters form centers of cluster development in the regions, are the result of the participation of state authorities in cluster management (Skvortsov and Guskova, 2016).

In the course of the study, it was concluded that the production of electricity from renewable sources is a promising direction for the development of a cluster economy, in which there is innovation. Innovative energy clusters are points of economic growth of territories that can change the infrastructure of energy companies. An innovative energy cluster is being formed on the basis of a large generating or transmission company. It includes small and medium-sized businesses, start-ups, representatives of the scientific community, capable of meeting the needs of an energy company in equipment, services, qualified personnel, the creation and implementation of scientific developments and innovations. The task of the state is to regulate the process of including innovative energy clusters in the unified energy network of Russia. We believe that large energy and grid companies and enterprises are aware of the importance of developing alternative energy sources and can be a major participant in the cluster. The financial capabilities of large companies motivate scientific organizations, start-ups with their innovative projects, small and medium-sized businesses to be part of the cluster, introduce new technologies and participate in projects for the creation and development of bioenergy.

\section{Discussion and Recommendations}

In the face of economic and environmental challenges, innovative energy clusters are points of economic growth of territories and provide diversification of the energy system of Russia ${ }^{11}$, by generating electricity from renewable sources.

The processes of creating international innovative energy, the inclusion of small and medium-sized businesses, start-ups, efficiency, flexibility, efficiency of building inter-cluster relationships depend on the solution of a number of problems that hinder the development of innovative energy and bioenergy clusters in Russia.

\footnotetext{
${ }^{11}$ Energy diversification means using different energy sources, suppliers and routes to reduce dependence on one resource or supplier. A country that diversifies its energy mix, insulates itself from energy disruptions, and strengthens its energy security // https://share.america.gov/ru/
} 
Currently, the Russian cluster map does not have a complete database of cluster formations, in contrast to the database located on the American and European cluster maps. The list of energy clusters is not complete, since the information to be placed on the cluster map is submitted to the Cluster Observatory on an application basis. Many companies, not having the proper motivation, do not declare themselves and do not transmit to the Cluster Observatory the information necessary and sufficient for their placement on the cluster map. On the Russian cluster map, innovative energy clusters are included in various groups of specializations.

Thus, the group of specialization "Production of electricity and electrical equipment" includes: Power cluster of the Tula region; Altai cluster of power engineering and energy efficient technologies. The group of specialization "Nuclear and radiation technologies" includes: Industrial nuclear cluster in the Tomsk region; Volgodonsk industrial cluster of nuclear engineering; Nuclear innovation cluster in the Dimitrovgrad city, Ulyanovsk region; Cluster of innovative technologies ZATO in Zheleznogorsk, Krasnoyarsk region; Sarovskii innovation cluster in the Nizhny Novgorod region. There are no bioenergy clusters in the above list.

The lack of complete summary information on Russian clusters creates the following difficulties. For scientists, it makes it difficult to conduct a comprehensive analysis of the cluster development of the Russian economy, for business building interconnections between clusters of related industries, for public authorities monitoring the implementation of cluster policy and state audit of the implementation of strategic planning documents.

The solution to the problem is seen in ensuring state regulation of the process of collecting statistical information on the results of activities of innovative energy and bioenergy clusters, as well as in increasing the social responsibility of generating and grid energy companies in Russia for transferring information to the Cluster Observatory. The formation of a complete database on clusters and cluster initiatives, including in the energy sector, will allow building relationships between clusters of related industries, monitoring the implementation of cluster policy and energy security strategy, providing targeted support to cluster initiatives in the field of bioenergy and the development of renewable energy sources.

Another problem was revealed as a result of a comparative analysis of the databases of the Cluster Map of Russia, the Cluster Map of the United States and the European Cluster Map.

Comparable groups of specializations of American and European clusters practically coincide, which ensures comparability of databases, maintenance of a unified accounting system for international clusters, and interaction of international clusters. The European and American cluster standardization system makes it possible to compare clusters by region, build interindustry links. Grouping and codification of clusters allows them to be identified, to calculate indicators of efficiency, 
competitiveness, etc.

However, the names and number of specialization groups of Russian clusters used in the course of cluster mapping differ significantly from comparable groups of specializations of American and European clusters, which is a certain obstacle to building international cluster relationships.

The Russian cluster map contains information about clusters grouped by 36 specializations. The US Cluster Map contains tradable (interregional) clusters grouped by 51 specializations. Tradable (interregional) clusters include groups of related industries that serve markets outside the region in which they are located. They can freely choose their place of activity (unless the location of natural resources determines their location), are concentrated in several regions and tend to be created only in those regions that provide certain competitive advantages (Delgado et al., 2014). The definition of tradable (interregional) clusters applies to Russian clusters as well. In the course of the study, we compared the groups of specializations of the traded clusters of Russia and the USA (Table 3).

Table 3. Comparison of specializations' groups of Russian and US clusters

\begin{tabular}{|c|c|}
\hline Cluster specializations in Russia & $\begin{array}{l}\text { Specializations of US Interregional } \\
\text { Clusters }\end{array}$ \\
\hline $\begin{array}{l}\begin{array}{l}\text { 1. Electricity and electrical equipment } \\
\text { production }\end{array} \\
\end{array}$ & 1. Electric Power \\
\hline 2. Extraction of crude oil and natural gas & 2. Oil \& Gas \\
\hline \multicolumn{2}{|l|}{ 3. Nuclear and radiation technologies } \\
\hline \multirow{2}{*}{ 4. Mining and quarrying } & 3. Nonmetal Mining \\
\hline & 4. Coal Mining \\
\hline \multirow{4}{*}{$\begin{array}{l}\text { 5. Metallurgy, metalworking and production of } \\
\text { finished metal products }\end{array}$} & 5. Metal Mining \\
\hline & 6. Upstream Metal Manufacturing \\
\hline & 7. Downstream Metal Products \\
\hline & 8. Metalworking \\
\hline \multicolumn{2}{|l|}{ 6. Aircraft construction } \\
\hline \multicolumn{2}{|l|}{ 7. Space industry } \\
\hline \multicolumn{2}{|l|}{ 8. Defense industry } \\
\hline \multicolumn{2}{|l|}{ 9. New materials } \\
\hline $\begin{array}{lll}\text { 10. Information } & \text { and } & \text { communication } \\
\text { technologies } & & \\
\end{array}$ & 10. IT \\
\hline \multirow{2}{*}{ 11. Automotive and auto parts manufacturing } & 11. Automotive \\
\hline & 12. Trailers \& Appliances \\
\hline $\begin{array}{l}\text { 12. Production of railway locomotives and } \\
\text { rolling stock }\end{array}$ & $\begin{array}{l}\text { 13. Production Technology and Heavy } \\
\text { Machinery }\end{array}$ \\
\hline \multirow{2}{*}{ 13. Chemical production } & 14. Downstream Chemicals \\
\hline & 15. Upstream Chemicals \\
\hline \multirow{2}{*}{ 14. Manufacture of rubber and plastic products } & 16. Plastics \\
\hline & 17. Vulcanized Materials \\
\hline 15. Transport and logistic & 18. Transport and logistic \\
\hline
\end{tabular}




\begin{tabular}{|c|c|}
\hline Cluster specializations in Russia & $\begin{array}{l}\text { Specializations of US Interregional } \\
\text { Clusters }\end{array}$ \\
\hline 16. Shipbuilding & 19. Water Transport \\
\hline \multirow{3}{*}{$\begin{array}{l}\text { 17. Forestry and woodworking; pulp and paper } \\
\text { production }\end{array}$} & 20. Forestry \\
\hline & 21. Wood Products \\
\hline & 22. Paper \& Packaging \\
\hline 18. Furniture manufacture & 23. Furniture \\
\hline \multicolumn{2}{|l|}{$\begin{array}{l}\text { 19. Production of building materials and other } \\
\text { products from glass, concrete, cement, plaster, } \\
\text { clay, ceramics and porcelain }\end{array}$} \\
\hline $\begin{array}{l}\text { 20. Construction, urbanization, architecture and } \\
\text { technical testing }\end{array}$ & $\begin{array}{l}\text { 24. Construction (local real estate, } \\
\text { construction and development } * \text { ) }\end{array}$ \\
\hline \multirow{4}{*}{$\begin{array}{l}\text { 21. Manufacture of textiles, clothing, footwear, } \\
\text { leather products }\end{array}$} & 25. Textiles \\
\hline & 26. Footwear \\
\hline & 27. Apparel \\
\hline & 28. Leather Products \\
\hline 22. Manufacture of sporting goods, toys & 29. Cultural goods \\
\hline 23. Jewelry manufacturing & 30. Jewelry \\
\hline \multirow{3}{*}{ 24. Agriculture and fishing } & 31. Agriculture \\
\hline & 32. Fishing \\
\hline & 33. Livestock \\
\hline \multirow{2}{*}{$\begin{array}{l}\text { 25. Manufacture of food, beverages and tobacco } \\
\text { products }\end{array}$} & 34. Food Processing \\
\hline & 35. Tobacco \\
\hline 26. Optics and Photonics & 36. Lighting \\
\hline 27. Microelectronics and instrumentation & $\begin{array}{l}\text { 37. Communication equipment and } \\
\text { services }\end{array}$ \\
\hline 28. Environmental protection and recycling & 38. Environmental Services \\
\hline 29. Pharmaceuticals & \multirow{2}{*}{ 39. Biopharma } \\
\hline 30. Industrial biotechnology & \\
\hline 31. Medical industry & 40. Medical Devices \\
\hline 32. Health care and social services & Local health services (local clusters) \\
\hline 33. Education & 41. Education \\
\hline 34. Tourism & 42. Hospitality \& Tourism \\
\hline \multirow{4}{*}{$\begin{array}{l}\text { 35. Mass media, television and film industry, } \\
\text { publishing and printing activities }\end{array}$} & 43. Printing \\
\hline & 44. Video Production \\
\hline & 45. Music \\
\hline & 46. Performing Arts \\
\hline \multirow{5}{*}{ 36. Business Services } & 47. Business Services \\
\hline & 48. Financial Services \\
\hline & 49. Marketing \\
\hline & 50. Insurance \\
\hline & 51. Distribution \& eCommerce \\
\hline
\end{tabular}

Source: Author's based on the data from maps of Russian clusters ${ }^{12}$ and $U_{S A}{ }^{13}$

\footnotetext{
${ }^{12}$ Russian Cluster Observatory. https://map.cluster.hse.ru/.

${ }^{13}$ US Cluster Mapping. https://clustermapping.us/.
} 
Comparative table of specializations of Russian and American clusters reveals similarities and differences. So, in the list of specializations of US interregional clusters there is no group "Nuclear and Radiation Technologies". At the same time, nuclear power generation in the United States accounts for more than $19.5 \%$ of the total electricity generation. At the beginning of 2019, the United States ranked first in the world in terms of the total capacity of operating nuclear power plants, which is 99,535 MW. The US nuclear power industry includes 99 operating reactors, four reactors are under construction.

For comparison, Russia is in fifth place in terms of nuclear power generation. The total capacity of 35 operating reactors of Russian NPPs is $26,865 \mathrm{MW}$, which is approximately $19 \%$ of the total demand in the country. Seven more reactors are under construction ${ }^{14}$. For identification and comparability of clusters of specialization groups, it is advisable to add to the list of specializations of American and European clusters the group "Nuclear and Radiation Technologies". Similar clarifications can be introduced for other groups of specializations.

Solving the tasks of creating an interactive cluster map, reflecting an exhaustive amount of data on clusters, as well as clarifying the specializations of Russian clusters, in accordance with European (American) specializations, will allow developing international clusters, as well as building interconnections between clusters of related industries. Building inter-cluster relationships will allow stakeholders to expand markets for products, find economic partners, attract labor resources, investors, and build logistics. The concept of "cluster" in the modern sense is becoming broader, and cluster ties arise primarily from business interests, and not from territorial or industry localization (Fonotov and Bergal, 2019a; 2019b). Cluster specializations allow you to make various combinations of inter-cluster relationships. Let us consider the operation of the IT-platform of clusters using the example of energy. We believe that cluster chains between various energy clusters and clusters of related industries can be built as economic interaction develops.

According to the American cluster map, the cluster of specialization "Production and transmission of electricity" is associated with clusters assigned to the specializations "Distribution" and "Production of crude oil and natural gas". The number of cluster relationships is minimal. Let us see how a similar network model can be updated for a Russian cluster map. We believe that Russian clusters assigned to the specialization "Production of electricity and electrical equipment" are associated with clusters of specializations "Nuclear and radiation technologies", "Extraction of crude oil and natural gas", "Metallurgy, metalworking and production of finished metal products"; "Transport and logistics", as well as with industrial clusters, which are the main consumers of electricity (Figure 3).

${ }_{14}$ NPP of the World. Top 10 countries: number of nuclear power plants and nuclear reactors (2014). https://miraes.ru/aes-mira-top-10-stran-po-kolichestvu-yadernyih-reaktorov/ . 
Figure 3. Scheme of the relationship of clusters of related industries

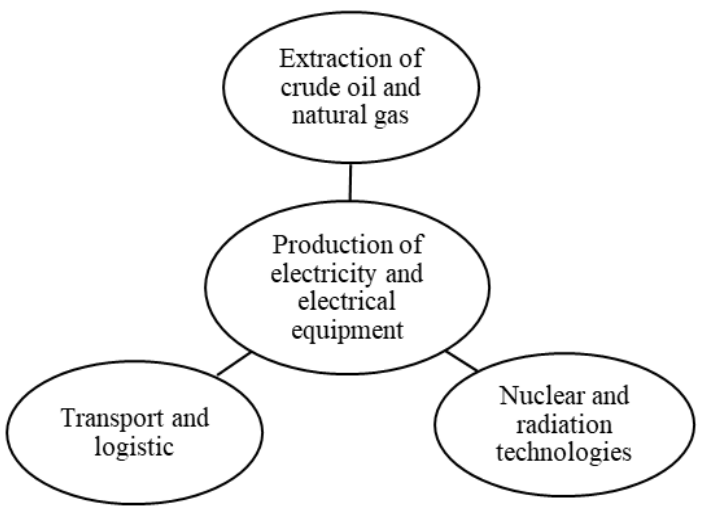

Source: Compiled on the basis of specializations of Russian clusters.

The clusters assigned to the Crude Oil and Natural Gas Extraction specialization are associated with the following clusters assigned to the Chemical Production specialization: Petrochemical territorial cluster of the Republic of Bashkortostan; Petrochemical cluster of the Tomsk region; Cluster of oil refining and petrochemistry of the Omsk region.

Clusters assigned to the specialization "Metallurgy, metalworking and production of finished metal products" are associated with clusters assigned to the specializations "Space industry", "New materials", "Defense industry", "Mining and quarrying", etc.

As part of the implementation of the state program Information Society, the program for the spatial development of Russia, is proposed to implement a resource for creating an IT platform, a kind of system integrator of clusters, which allows building inter-cluster chains and interconnections of clusters of related industries.

\section{Conclusion}

The results of the study made it possible to confirm the hypothesis that innovative energy clusters participate in the diversification of the national energy system through the development of bioenergy, the introduction of innovative energy-saving technologies, increasing energy efficiency, and also stimulate the growth of regional economies through the creation of new enterprises, jobs, and labor productivity growth. An innovative energy cluster, as a rule, includes a large energy company, small and medium-sized businesses, start-ups, representatives of the scientific community, capable of meeting the needs of an energy company in equipment, services, qualified personnel, creating and implementing scientific developments and innovations (Pociovalisteanu et al., 2015). 
As an element of scientific novelty, it is possible to highlight the recommendation to create an IT-platform of clusters on the basis of the Map of Clusters of Russia, which will allow cluster entities to build inter-cluster chains and interconnections of clusters of related industries, to intensify the transfer of new and creation of promising commercial technologies, new products, to attract resources for research and developments with the participation of business, science and government.

During the implementation of the state program "Information Society" on the basis of the Cluster Observatory, it is proposed to create a complete database of existing clusters and cluster initiatives, including in the energy sector. This will allow building relationships between clusters of related industries, monitoring the implementation of cluster policy and energy security strategy, providing targeted support to cluster initiatives in the field of bioenergy and the development of renewable energy sources.

The study clarifies the specialization of Russian clusters, taking into account the specializations of American and European clusters, which are almost identical, which will ensure the comparability of databases and simplify network interactions with foreign clusters. The conclusions and proposals obtained in the course of the study can have practical application in the process of updating the strategic planning documents.

\section{References:}

Alekseev, A.N., Bogoviz, A.V., Goncharenko, L.P., Sybachin, S.A. 2019. A Critical Review of Russia's Energy Strategy in the Period until 2035. International Journal of Energy Economics and Policy, 9(6), 95-102.

Bulyarsky, S.V., Bulyarskaya, S.V., Sinitsyn, A.O. 2012. Industrial cluster management. Bulletin of OSU, 9, 70-74. (In Russian).

Delgado, M., Porter, M., Stern, S. 2014. Defining Clusters of Related Industries. NBER Working Paper No. 20375. National Bureau of Economic Research, 1-48.

Demirbas, A. 2008. Biofuels sources, biofuel policy, biofuel economy and global biofuel projections. Energy Conversion and Management, 49(8), 2106-2116.

Fakhrutdinova, E.V., Rodnyansky, D.V. 2016. Energy clusters analysis and their impact on the socio-economic development of the Russian regions. Economic Sciences, 142, 26-30. (In Russian).

Fonotov, A.G., Bergal, O.E. 2019a. Territorial Clusters as a Mechanism for Spatial Development of Russian Economy. Journal of Economic Theory, 16(4), 673-687. (In Russian).

Fonotov, A.G., Bergal, O.E. 2019b. Audit of effectiveness of the government support of territorial clusters - drivers of economic growth. ACM International Conference Proceeding Series. International SPBPU Scientific Conference on Innovations in Digital Economy, 1-7.

Glăvan, B. 2008. Coordination failures, cluster theory, and entrepreneurship: A critical view. Journal of Austrian Economics, 11(1), 43-59.

Glaz'ev, S.Yu., Ivanter, V.V., Makarov, V.L., et al. 2011. About the development strategy of the Russian economy. Economic science of modern Russia, 3(54), 7-31. (In 
Russian).

Gokhberg, L., Klepach, A., Rudnik, P. (Eds.) 2016. Guidelines for Composing and Implementing Programmes for the Development of Innovative Regional Clusters and Regional Cluster Policy. Ministry of Economic Development of the Russian Federation, National Research University Higher School of Economics. Moscow, HSE, 208.

Golovanova, S.V., Avdasheva, S.B., Kadochnikov, S.M. 2010. Intercompany cooperation: cluster development analysis in Russia. Russian Management Journal, 8(1), 41-66. (In Russian).

Iazzolino, G., Carolis, M., Clemeno, P. 2019. Energy Innovative Start-ups and Knowledgebased Strategies: The Italian Case. International Journal of Energy Economics and Policy, 9(5), 88-102.

Kalmykova, Y., Rosado, L., Patrício, J. 2016. Resource consumption drivers and pathways to reduction: economy, policy and lifestyle impact on material flows at the national and urban scale. Journal of Cleaner Production, 132, 70-80.

Kapitonov, I.A., Taspenova, G.A., Meshkov, V.R., Shulus, A.A. 2017. Integration of Small and Middle-sized Enterprises into Large Energy Corporations as a Factor of Business Sustainability. International Journal of Energy Economics and Policy, 7(2), 44-52.

Kapoguzov, E.A., Chupin, R.I., Kharlamova, M.S. 2019. Cluster policy of regional development: resources and institutional conditions. Journal of Economic Theory, 16(1), 22-36. (In Russian).

Kleyner, G.B. 2018. Industrial ecosystems: view into the future. Economic revival of Russia, 2(56), 53-62. (In Russian).

Konstantynova, A. 2019. Cluster policy change and evolution: Facilitating regional smart specialisation and economic development. International Journal of Globalisation and Small Business, 10(2), 127-142.

Kostenko, O.V. 2016. Methodological approaches to building a cluster development strategy. Russian Journal of Entrepreneurship, 17(16), 1945-1958. (In Russian).

Kousoulidou, M., Lonza, L. 2016. Biofuels in aviation: Fuel demand and CO2 emissions evolution in Europe toward 2030. Transportation Research Part D Transport and Environment, 46, 166-181.

Koytsoumpa, E., Bergins, C., Buddenberg, T., Wu, S., Sigurbjörnsson, Ó., Tran, K.C., Kakaras, E. 2016. The Challenge of Energy Storage in Europe: Focus on Power to Fuel. Journal of Energy Resources Technology, 138(4), 1-10.

Kutsenko, E. 2015. Pilot Innovative Territorial Clusters in Russia: A Sustainable Development Model. Foresight-Russia, 9(1), 32-55.

Larionova, N.I., Yalyalieva, T.V., Napolskikh, D.L. 2018. Global competitiveness, neoindustrialization and innovative clusters: International indicators and trends of Russian federation. RevistaGalega de Economia, 27(2), 125-138.

Markov, L.S. 2006. Economic clusters as a form of functioning and development of the region's industry: the example of high technology clusters. RAN, IEOPP SB RAS Novosibirsk, 186. (In Russian).

Melnik, A.N., Sadriev, A.R. 2013. Challenges and opportunities for the energy clusters formation. World Applied Sciences Journal, 27(13), 194-197.

Melnik, A.N., Ermolaev, K.A. 2019. Conceptual framework for managing energy conservation and energy efficiency in an industrial enterprise in the context of its innovative development. Economic analysis: theory and practice, 18(1), 22-39. (In Russian). 
Mikova, N., Eichhammer, W., Pfluger, B. 2019. Low-carbon energy scenarios 2050 in northwest European countries: Towards a more harmonised approach to achieve the EU targets. Energy Policy, 130, 448-460

Minakir, P.A. 2019. Russian economic space. Strategic deadlocks. Economy of region, 15(4), 967-980. (In Russian).

Pociovalisteanu, M.D., Thalassinos, I.E., Tirca, A. and Filho, L.W. 2010. Trends and challenges in the energy sector of Romania in the post-accession to the European Union. International Journal of Environmental Technology and Management, 12(1), 3-15, DOI: 10.1504/IJETM.2010.029957.

Schanes, K., Jäger, J., Drummond, P. 2019. Three Scenario Narratives for a ResourceEfficient and Low-Carbon Europe in 2050. Ecological Economics, 155, 70-79.

Sheresheva, M.U. 2008. Clusters. Collection of regional aspects of the formation of the national innovation system of Russia. Moscow, Statut, 335. (In Russian).

Skvortsov, E.N., Guskova, N.D. 2016. Analysis of the organizational structures of innovation industrial cluster management systems in Russia. Scientific and Technical Journal of St. Petersburg State Polytechnic University. Economic sciences, 1, 86-99. (In Russian).

Sölvell, Ö., Ketels, C., Lindqvist, G. 2009. EU Cluster Mapping and Strengthening Clusters in Europe. Luxembourg, Publications Office of the European Union, 31.

Tret'jak, V.P. 2006. Enterprise clusters. https://www.rfbr.ru/rffi/ru/books/o_72132. (In Russian).

Tsathlanova, T.T., Idzhilova, D.V., Erdnieva, E.V. 2015. The problem-oriented analysis of regional cluster policy development in the Russian Federation. Mediterranean Journal of Social Sciences, 6(4), 333-339.

Tsikhan, T.V. 2003. Cluster theory of economic development. Theory and practice of management, 5, 43-51. (In Russian).

Tyaglov, S.G., Sheveleva, A.V., Shurukhina, T.V., Guseva, T.B. 2019. Model for Forming the Interregional Cluster of the Alternative Energy. International Journal of Energy Economics and Policy, 9, 373-378. 